* Doutoranda e Mestre em Direito pela Universidade de Santa Cruz do Sul (UNISC). Professora da Faculdade de Direito no Centro Universitário UNIVATES em Lajeado/RS. Membro do Grupo de Pesquisa Comunitarismo e Políticas Públicas, vinculado ao CNPq. E-mail: eliane.fontana859@gmail.com

* * Pós-Doutor em Direito pela Universidade de Lisboa. Doutor em Direito pela Universidade do Vale do Rio dos Sinos (UNISINOS). Mestre em Direito pela Universidade de Santa Cruz do Sul (UNISC). Professor de Graduação e do Programa de Pós-Graduação em Direito Stricto Sensu da Universidade de Santa Cruz do Sul (UNISC). Chefe do Departamento de Direito da Universidade de Santa Cruz do Sul (UNISC) e Coordenador do Grupo de Estudos Gestão Local e Políticas Públicas (UNISC). E-mail: hermany@unisc.br

\section{O direito social condensado em Gurvitch e o comunitarismo de Ezioni: notas acerca de uma interconexão possível}

\author{
The SOCIAL RIGHTS CONDENSED INTO GURVITCH \\ AND THE COMMUNITARIANISM OF EZIONI: NOTES \\ ON A POSSIBLE INTERCONNECTION
}

* Eliane Fontana

** Ricardo Hermany

Resumo: Este artigo tem como objetivo geral uma investigação acerca da possível interlocução entre o direito social condensado trabalhado pela teoria de Georges Gurvitch e a corrente filosóficopolítica contemporânea do Comunitarismo Responsivo, de Amitai Etzioni. Busca-se evidenciar se há conexões possíveis no que tange às variáveis de similitudes e divergências. Concluiuse que, apesar das notáveis diferenças entre os seus autores, as teorias buscam algo em comum: a integração social numa ambiente democrático. $\mathrm{O}$ rechaço às posturas extremistas, que imprimem o individualismo é a forca motriz para a construção de um direito autorregulado pela sociedade- por Gurvitch- e, também, por Etzioni, neste, para o desenho de uma Plataforma que perfila uma terceira via ao individualismo e ao social conservadorismo.

Palavras-Chave: Amitai Etzioni. Comunitarismo. Direito social condensado. Georges Gurvitch.

Abstract: This paper aims an investigation into the possible dialogue between the Social Right condensed by Georges Gurvitch's theory and the current philosophical and political streaming of the Responsive Communitarism of Amitai Etzioni. It seeks evidences for possible connections between the variables of similarities and differences. It was concluded that, despite the notable differences between the authors, the theories seek something in common: social integration in a democratic environment. The rejection of extreme positions, that print individualism, is the driving force to the construction of a selfregulated rights by the society [Gurvitch] and also by Etzioni, in which, to design a Platform that works like a third way to individualism and social conservatism.

Keywords: Amitai Etzioni. Communitarism. Condensed social right. Georges Gurvitch. 


\section{INTRODUÇÃO}

Num primeiro momento se trará algumas notas acerca da teoria do Direito Social Condensado teorizado por Gurvitch e o que ela proclama, em termos gerais, fundamentalmente no tocante à concepção de uma comunidade autorregulada. Na sequência, se abordará o comunitarismo de Etzioni, no que tange aos seus aspectos mais importantes, tais como a ideia de uma boa sociedade e os diálogos morais compartilhados pela comunidade.

No terceiro ponto a ideia é dar relevo aos aspectos em que ambas as teorias buscam comumente alcançar, notadamente no que se relaciona ao contexto social, cada qual ao seu tempo. Gurvitch, que viveu a primeira metade do século XX e mesmo antes de vivenciar a ideia de um Walfare State, construiu uma proposta que dá à sociedade as formas de buscar as promessas da modernidade. Já Etzioni, que inicia sua vida acadêmica na segunda metade século XX e tornou-se expoente de uma corrente filosófica chamada de comunitarismo responsivo, bem como construtor de uma proposta teórica com bases sociológicas fortes que se apresentada como terceira via, em favor da renovação do projeto do Welfare State - por ele vivido.

Veja-se que, entre as diferenças cronológicas é possível visualizar uma conexão entre amas as propostas e que dá o contributo para estas notas iniciais sobre a investigação de correntes tão importantes para a atual reflexão acadêmica do direito. O trabalho é puramente bibliográfico e tem como fundamentação teórica as obras dos autores referendados, primordialmente.

\section{O DIREITO SOCIAL CONDENSADO DE GURVITCH: A SOCIEDADE AUTORREGULADA}

Para contrapor-se a todo um arcabouço levantado a partir da segunda metade do século XIX sob a ótica individualista, tanto social como jurídica, a teoria abordada na obra de Georges Gurvtich, chamada La idea de derecho social, visa trabalhar a comunidade autorregulada. $\mathrm{O}$ autor reforça de que cada grupo em si propõe uma forma promotora de uma espécie de direito, divorciada da ideia estatizada do mesmo. A vida interna de uma comunidade - seja ela qual for - é por ela regulada de maneira a não necessitar existir a coação direta como apanágio. 
Em que pese à sinonímia, há que se fazer de início a ressalva de que o Direito Social trabalhado na perspectiva de Georges Gurvitch não se correlaciona com o desenho de Direto Social (Estado Social/Providência/ Bem-Estar Social) delineado em meados do século XX, que foi,

[...] históricamente el intento de adaptación del Estado tradicional (por el que entendemos en este caso el Estado liberal burgués) a las condiciones sociales de la civilización industrial y postindustrial con sus nuevos y complejos problemas, pero también con sus grandes posibilidades técnicas, económicas y organizativas para enfrentarlos. No hemos de ver las medidas de tal adaptación como algo totalmente nuevo, sino más bien como un cambio cualitativo de tendencias surgidas en el siglo XIX y comienzos del XX para regular, en aquel entonces, aspectos parciales de la sociedad, regulación que sufre en nuestro tiempo un proceso de generalización, integración y sistematización (GARCÍA-PELAYO, 1996. p. 18).

Todavia, após a o intento de força social pós-industrial, por ocasião dos princípios do Consenso de Washington, combinados entre os países centrais em meados dos anos 80 do século XX, e "impostos" pelas agências financeiras multilaterais ${ }^{1}$ (como é o caso do Banco Mundial, o Fundo Monetário Internacional e a Organização Mundial do Comércio) instituiuse outra perspectiva, agora neoliberalista da economia insculpida numa intervenção mínima do Estado (MARQUES, 2008). O consenso de Washington impunha, assim, a transição do welfare para o worfare. (SANTOS, 2000).

Muito além da ideia de direito social advinda do século XX a qual se destaca o Estado Providência mencionado, a promoção de direitos mais coletivizados é a proposta de Gurvitch, que busca um espaço normativo cognitivo, relacionado à comunicação e a interlocução dos membros internos de um grupo. Fala-se em comunhão, integração, autonomicidade. Um direito que vem do todo, independente de hierarquia e organização, mas valorado no poder social que vem de dentro pra fora do seio de uma comunidade.

\footnotetext{
${ }^{1}$ Foi com certeza um o Estado-Providência, já que se sentenciava o fim desse modelo de Estado, através da privatização da segurança social, da diminuição da intervenção estatal e da substituição das políticas sociais por medidas residuais dirigidas especificamente para as situações mais extremas de pobreza.
} 
Considera-se a existência de um direito de integração, de um direito gerado de maneira autônoma pela vida coletiva do grupo, integrando as suas tradições, as suas necessidades e as suas aspirações, sendo fundamental que haja uma correlação com os princípios constitucionais como mínimo referencial, o que implica a superação do binômio estatização/privatização por uma estratégia que privilegie um contexto de integração entre sociedade e espaço público estatal (HERMANY, 2007), em função de que Gurvitch propõe,

[...] un derecho autónomo de comunión, que integra de forma objetiva cada totalidad activa real, que encarna un valor positivo extratemporal. Este derecho se deriva directamente del todo en cuestión para regular su vida interior, independientemente del hecho de que este todo esté organizado o in-organizado. El derecho de comunión hace participar al todo de forma inmediata en la relación jurídica que enana de él, sin transformar este todo en un sujeto separado de sus miembros. [...] El derecho social precede, en su fase primaria. A cualquier organización del grupo y no se puede expresar de forma organizada más que si la asociación está fundada en el derecho de la comunidad subyacente objetiva y penetrada por ella, es decir, cuando constituye una asociación igualitaria de colaboración y no una asociación jerárquica de dominación. (GURVITCH, 2005, p. 19).

Bem como a construção de um paradigma intermediário, situado entre o procedimentalismo e o substancialismo ${ }^{2}$, ele é, basicamente,

[...] um direito como fato social, que encontra sua legitimidade a partir da própria sociedade, estabelecendo-se nitidamente uma lógica reflexiva, segundo a categoria habermasiana ${ }^{3}$, pois os autores sociais

\footnotetext{
2 A diferença é trabalhada na obra de Hermany (2007, p. 75) "Nota-se, portanto, que nas duas propostas o texto constitucional, forte em seus princípios, ocupa posição destacada, havendo uma divergência, isto sim, em relação aos atores responsáveis por sua consolidação e atribuição de sentido. Enquanto os procedimentalistas enfatizam o papel da comunidade de intérpretes, os substancialistas reiteram a importância da atuação do Judiciário."

3 O direito idealizado por Gurvitch não está divorciado de umas das teorias mais estudadas acerca da democracia, que é a Teoria da Ação Comunicativa de Habermas. Para Habermas (2003, p. 25) as comunicações políticas, filtradas deliberativamente, dependem das fontes do ele chama de " mundo da vida" - de uma cultura política libertária e de uma socialização política esclarecida, especialmente das iniciativas de associações que formam opinião - as quais se formam e se regeneram quase sempre de modo espontâneo, dificultando as intervenções diretas do aparelho político. Assim, a teoria do discurso considera o sistema político como um sistema de ação ao lado de outros, mas não o principal e nem o centro da sociedade.
} 
são simultaneamente autores e destinatários do direito (HERMANY, 2006, p. 30)

Assim, com base numa atuação reflexiva da sociedade, o direito encontra sua garantia no reconhecimento social, a partir da atuação engajada dos quadros sociais estruturados ou não (organizados ou não ${ }^{4}$ ). $\mathrm{O}$ hecho social tão difundido em Gurvitch seria a elaboração, pela sociedade, de normativas que regrariam a vida em comunidade. Se a sociedade se engaja para a construção de suas leis ela concorda e palpita na gestão pública dos ditames que ela mesma terá de cumprir, numa perspectiva de gestão compartilhada.

Como toda a teoria, naturalmente há análise crítica (limites) desse fenômeno do direito social, notadamente pelo fato de que, em se desenhando uma via normativa para a sociedade, se deixaria sem limites - e, portanto, com possibilidade de abusos - tal papel legiferante. Para tal, é necessário que haja um referencial mínimo capaz de garantir as conquistas sociais, sob pena do retorno ao paradigma liberal ${ }^{5}$, de acordo com Hermany (2006). Há também que se aferir a questão do poder do mercado globalizado: já que dominação exercida pelas ordens não-estatais relacionadas ao setor empresarial, além de superar o ordenamento estatal, desvinculando-se dos princípios constitucionais, impedem o direito oriundo das organizações de natureza social, como sindicatos e as convenções coletivas de trabalho (HERMANY, 2006, p. 37).

Ainda, no que concerne aos referenciais mínimos é preciso alertar que Um reducionismo alicerçado tão-somente num sentimento de solidariedade global, a partir do qual a sociedade estabelece a auto legislação e forma as decisões públicas, contraria frontalmente a ideia de direito reflexivo é na Constituição que se encontram os princípios informativos que devem ser concretizados a partir da atuação reflexiva da sociedade (HERMANY, 2006, p. 54).

Assim, o tipo de direito social que atenderia a esses anseios e daria azo a imposição desses limites seria, segundo Gurvitch, um Direito Social Condensado:

\footnotetext{
${ }^{4}$ Para Gurvitch (2005, p. 63) a ideia de um direito não organizado é " un derecho social independiente, ya que predomina sobre el derecho de la comunidad politica y de s superestructura organizada, el Estado, al igual que sobre el derecho de la comunidad económica: él regula las funciones y competencias de éstos".

${ }^{5}$ Para Hermany (2006, p. 50), a elaboração autônoma de normas, através de uma arranjo comunicativo, amparada no princípio do discurso, não pode ser entendida como uma possibilidade ilimitada da sociedade, através de um somatório simplificado de vontades individuais.
} 
[...] Si el "derecho constitucional" de la organización estatal está penetrado por el derecho social que se desprende de la comunidad politica subyacente, hacemos referencia a un derecho social, derecho social consensado en el orden del derecho estatal por su ligazón con la coacción incondicionada. Si esta penetración no ha tenido lugar, si la organización del Estado es más o menos independiente de la infraestructura de la comunidad politica subyacente, se trata entonces de un orden subordinado y non de un derecho social. (GURVITCH, 2005, p. 94).

Para o autor, essa concepção de direito social, que relativizaria a ideia de um direito social puro ${ }^{6}$, permitiria que se estabelecessem elementos de conexão entre o processo de coordenação e integração dos atores sociais no processo de organização da sociedade, sem se afastar das garantias mínimas inclusas no texto constitucional.

A noção intermediária propõe que as normas jurídicas emanadas pela sociedade se mostrem condensadas a uma estrutura de Estado Democrático e, sua efetivação, como ordem de integração social, está intrinsecamente relacionada à assunção pela sociedade de seu papel de sujeito ativo no processo de atribuição de sentido ao texto constitucional de um Estado Democrático (HERMANY, 2006).

O sentido de integração, para justificar a construção de um Direito Social Condensado é trabalhado por Gurvitch numa concepção de entrelaçamento de interesses entre os membros de uma sociedade,

En el proceso de integración social se encuentran y se unen dos movimientos diferentes: el todo si integra a si mismo mediante la integración de los miembros en su seno.[...] "Integrar "a un miembro en el "todo" significa: hacerlo participar en este todo como un elemento de generación de su totalidad y según los principios de su unidad, sin someter sin embargo el elemento integrado en un poder unilateral (GURVITCH, 2005, p. 22).

\footnotetext{
${ }^{6}$ A forma pura de Direito Social- matriz da teoria de Gurvitch é impraticável no plano fático, tendo em vista as falhas do excesso de abertura à elaboração normativa - pela sociedade- enquanto somatório de vontades individuais, sem os limites necessários, e tendenciosa à volta do ideal liberal. $\mathrm{O}$ autor expõe sua ideia de pureza quando diz que [..]el derecho social puro debe cederle el lugar e inclinarse ante él. Exteriormente, esta sumisión se manifiesta por la clasificación del derecho social puro en los ámbitos del derecho privado, lo que denota que la oposición entre el derecho privado y el derecho público, dependiente del orden del derecho estatal, es aplicable a esta realidad jurídica. (GURVITCH, 2005, p. 70)
} 
O que se pode verificar é que, para o autor, o envolvimento da sociedade na construção de normas que conviveriam em harmonia com o a produção legal do Estado Democrático, relevaria verdadeiramente suas vontades, tendo em vista de "o todo" "não pode diluir as inúmeras discussões contidas na coletividade que o processo formal de elaboração de normas acaba suprimindo. Nesse sentido, verifica-se uma sociedade como o sujeito ativo no controle das decisões públicas e na produção do Direito, objetivando a obtenção do consenso.

Nota-se que a sociedade desenhada por Gurvitch é um ideal de coletividade engajada e, acima de tudo, preocupada com a auto-organização de seu espaço. Esse é o ponto de toque entre a parte até aqui trabalhada e àquela que se vai desvelar no ponto seguinte: que tipo de sociedade e de relação(comunicação) é necessário para que se realize o Direito Social Condensado? De que tipo de sociedade se poderia pressupor? Talvez a resposta desse questionamento estaria nos estudos de Amitai Etzioni quando trabalha a ideia de uma boa sociedade. As regras que limitam o poder das comunidades, segundo Etzioni (2000, p. 50 -51), devem ser reduzidas de forma a eliminarem barreiras às comunidades e, além disso, removerem, também, barreiras aos Estados e aos mercados. A boa sociedade conceituada na obra La terceira Via consegue alcançar seu equilíbrio mediante as restrições que seus elementos se impõem entre si..

Para Etzioni (2000, p. 17), uma sociedade que não seja somente sociedade civil, mas uma boa sociedade, a qual alimenta as relações Eu-tu, com valores que buscam limitar os conflitos e as batalhas culturais e alcançar compreensões compartidas. Uma sociedade em que todos são tratados com respeito, onde todos têm condições de atingir seu mais completo potencial humano tem-se simultaneamente; direitos individuais e responsabilidades sociais para com todos.

Diante dessa possível conjectura de teorias que, ao final, podem vir a idealizar sociedades enobrecidas e autorregulamentadas, passa-se a discorrer de maneira mais especifica para alguns conceitos chaves de Etzioni que encontrariam pontes nesse viés condensado de direito social de Gurvitch.

7 Para Morais, "[...] Trata-se da noção de pessoa coletiva complexa que permite ao direito social a legitimidade democrática sem ofuscar os grupos e indivíduos que se comportam como atores da ação comunicativa, que permeia a construção do consenso na sociedade, não havendo, conforme Morais(1997, p. 33), diluição do membro na totalidade." 


\section{A BOA SOCIEDADE EM ETZIONI: REFLEXÕES MORAIS COMPARTIDAS}

A boa sociedade é equilibrada num tripé formado pelo Estado, o mercado e a sociedade, todos adequadamente sustentados e limitados. As pessoas são fins e não meios, portanto, falar em Etzioni, é falar em uma bagagem moral da sociedade. Trata-se da responsabilidade de todos e para todos, pois a exclusão social é fator de desagregação social e a boa sociedade é universalista, defendendo Etzioni, o mutualismo (ajuda a todos) face ao voluntarianismo (ajuda ao necessitado).

Os diálogos sociais - e a importância de estuda-los - são o pano de fundo de um fundamento ético: o bem estar da comunidade. Os direitos sempre implicam em responsabilidades correspondentes. E entre os direitos e as obrigações existem conflitos acerca dos limites e valores que os ligam. Será que se deve ter autonomia e direitos individuais ilimitados? $\mathrm{Ou}$, ao revés, seria mais pertinente que a ordem social máxima se sobressaísse sob as vontades individualizadas? Para Etzioni, nem uma, nem outra. E, para este brevíssimo estudo, esta concepção interessa e vem a ser o foco na discussão acerca da sociedade descrita no ponto acima.

Nos estudos de Etzioni encontra-se um novo paradigma, qual seja, a nova regra de ouro ${ }^{8}$, baseada no equilíbrio entre ordem e autonomia ${ }^{9}$, onde a boa sociedade fomenta tanto os direitos individuais como as virtudes sociais (responsabilidades sociais). Isso porque "uma comunidade não é um lugar concreto, mas um conjunto de atributos." (ETZIONI, 1999, p. 26). A boa sociedade não é o domínio dos deveres impostos, pois apesar da diversidade, isto é, das tensões entre as preferências pessoais, toda comunidade tem valores compartidos, dos quais decorre a ordem comunitária de responsabilidades sociais fundadas em compromissos morais entre seus membros tornando-a legítima. Nas palavras do autor,

[..] el paradigma comunitario propuesto aplica la noción de la regla del oro en el ámbito social para caracterizar la buena sociedad

\footnotetext{
${ }^{8}$ A antiga regra de ouro seria a ide ade bem comum e ordem social e Etzioni defende sua releitura.

9 Esses elementos relacionam-se "simbioticamente", mas não se trata de que quanto mais ordem desenvolve uma sociedade menor será sua autonomia e o inverso e também não é uma questão de complementaridade. Os elementos se enriquecem mutuamente quando em conjunto, entretanto, quando um se sobressai o outro começa a diminuir e o equilíbrio desaparece e surge o antagonismo. (ETZIONI, 1999).
} 
como una sociedad que fomenta tanto las virtudes sociales como los derechos individuales. Yo afirmo que, más que la "maximización" de orden o de autonomía, lo que una buena sociedad requiere es un equilibrio mantenido entre uno y otra. (ETZIONI, 1999, p. 24).

Inclusa na ideia de boa sociedade está a voz moral ${ }^{10}$, que se dá quando o comportamento de cada membro da comunidade reflete em prol da sociedade, no reconhecimento de certas condutas como socialmente saudáveis. Mas como se cultivaria tal voz moral? Através da educação, pelo consenso e pela relevância de diálogos morais (acerca de valores compartilhados). Afinal, a ordem legal é que alcança os indivíduos e não o contrário. Quem cumpre responsabilidades apenas porque a lei as impõe, na realidade, não as reconhece. Assim,

[...] podría considerarse que la voz moral de la comunidad constituiría uno de los mejores antídotos en contra de un estado opresor, capaz de limitar la libertad de los individuos[...]Por tanto, la sociedad no se sostiene porque existe la ley sino porque se encuentra respaldada por el amparo moral de la propia comunidad. De este modo, el orden se alcanza mediante los instrumentos normativos que tienen que ver con la educación y el consenso, apartados de los medios de coerción, propios de los sistemas totalitarios o de los procedimientos mercantiles, tradicionalmente desarrollados en las sociedades libertarias. (SAN ROMÁN; PEDROSA, 2012, p. 47).

Ou seja, "as boas sociedades descansam muito mais na voz moral que na coerção.” (ETZIONI, 1999, p. 149). A voz moral é muito mais compatível com a autonomia individual do que a confiança na polícia, que é coercitiva. O direito não é a base primária da ordem, mas sim a continuação da moral por outros meios, sem moral as leis são inúteis. A voz moral, ainda que interna dos indivíduos só o é quando expressa na comunidade, esta é que confere a característica de voz moral. A comunidade então pode ser definida mediante duas características: um conjunto de relações carregadas

\footnotetext{
${ }^{10}$ Par Etzioni (1999, p. 150), a voz moral; "es una forma peculiar de motivación: alienta a la gente a adherirse a los valores que suscribe. Es peculiar porque, a diferencia de las motivaciones típicas, no es la persecución de una liberación fisiológica o psicológica[..] El sentido de afirmación que tiene la gente cuando se guía por valores es fundamentalmente distintos".
} 
de afeto entre grupo de indivíduos e o compromisso com um conjunto de valores compartidos, normas e significados. Por essas razões o principal estamento social não é o Estado e os atores principais não são os cidadãos, o estamento é a sociedade e os atores são seus membros.

Para o comunitarismo - corrente a qual Etzioni hoje é expoente- há momentos em que o "tudo ou nada" não trazem respostas, pois para certas decisões não há margem para se ceder. Como se resolveriam esses problemas? Por meio de diálogos morais. Os diálogos morais seriam uma espécie de comunicação acerca de valores, em relação às propostas normativas de uns para com os outros, ou seja, para com a comunidade. É dizer,

[...] los diálogos morales son una conversación sobre los valores. Si un determinado principio es compartido por todos los que dialogan estamos ante un acuerdo y constatamos que estamos ante un valor compartido [...] El objetivo va más allá del mero consenso coyuntural, se busca el acuerdo sustantivo (SAN ROMÁN; PEDROSA, 2012, p. 45).

E ocorrem através "de un proceso de especial importancia para aquellos que persiguen la buena sociedad: diálogo moral. Éste consite en una conversación mutua, un "toma y daca" en el salen a colación no meros intereses e deseos, sino fundamentalmente valores" (ETZIONI, 2001, p. 62). Tais diálogos se dariam por meio de três vias trabalhadas por Etzioni. Uma delas seria a busca de uma proibição a qual todos concordam e se sentem livres por tê-la como norma. Na sequência seria a criação de dois grupos com valores distintos, mas que buscam um objetivo comum. Por fim, a educação em valores, a persuasão e a liderança seriam caminho, muito embora o autor alerte que essa via seria a mais tênue e perigosa. Tais procedimentos seriam necessários por que os diálogos devem explorar

[...] todas las vías posibles para llegar a acuerdos sobre el fondo de la cuestión, sin contentarse con el mero establecimiento de diversas formas para evitar el choque. Aunque, obviamente, estos procedimientos para impedir esas colisiones tienen una enorme importancia. (SAN ROMÁN; PEDROSA, 2012, p. 49).

Também há que referir que os diálogos precisam ser regrados, e Etzioni coloca que uma das regras do jogo é que àqueles que se queixam deveriam 
assumir a responsabilidade de debaterem. Na obra La Nueva Regla del Oro o autor expõe uma lista de referências que contribuem para determinar até que ponto uma sociedade é ou pode ser comunitarista, sob o ponto de vista de assegurar-se de que novas práticas e políticas sejam:

Ante de todo, una sociedad comunitaria no adopta recursos coercitivos (como la policía, las cárceles y la regulación) a menos que sirvan para enfrentarles a un peligro claro y actual.

En segundo lugar, cuando las sociedades comunitarias se ven obligadas a actuar para contrarrestar un peligro claro y presente, deben comenzar por tratar de hacerle frete sin recurrir a medidas que restrinjan la autonomía.

En tercer lugar, en la medida que haya que introducir medidas que debiliten la autonomía, esas medidas han de ser lo menos intrusivas posible.

Por último, las sociedades comunitarias trabajan para minimizar los efectos colaterales - a menudo no intencionales-de la diminución de autonomía que entrañan las medidas que deban adoptarse en pro del bien común.

Un comunitario sostiene que la privacidad es un derecho individual que, lo mismo que otros, debe enmarcarse en un contexto socio histórico y sopesarse con las necesidades sociales de orden. (ETZIONI, 1999, p. 75).

A perspectiva de comunitarismo, tal qual se concebe nos textos de Etzioni, um renomado sociólogo israelense, radicado nos Estados Unidos, precursor do comunitarismo responsivo, apresenta a formulação de uma teoria abrangente das dimensões fundamentais da vida em sociedade, como a política, a economia, a educação, a ética e a cultura, com o objetivo de mostrar uma visão alternativa de mundo, uma terceira via ${ }^{11}$ em relação às concepções focadas no Estado e no Mercado (SCHMIDT, 2014, p. 4). Mas como seria essa terceira via?

Entre as linhas básicas da Plataforma encontram-se as seguintes: a importância da comunidade na existência humana; o indispensável

\footnotetext{
${ }^{11}$ Schmidt $(2014$, p. 8) destaca que "a clara opção pela terceira via, um caminho alternativo à esquerda e à direita norte-americana, sem deixar de contemplar valores centrais de uma e outra, especialmente as questões da liberdade e da autonomia individual, prezadas pela esquerda, e as da moral e da ordem, substanciais no ideário da direita".
} 
equilíbrio entre a liberdade e responsabilidade, entre o bem comum e a autonomia individual; o papel da voz moral frente ao Estado e ao mercado, exercido pela persuasão e pela educação; o fortalecimento da democracia através do incremento da representação, da participação e da responsividade da política em relação aos cidadãos; a centralidade dos valores e deveres cívicos, da ética na política; a afirmação da democracia forte, não apenas majoritária; a necessidade de repensar e apoiar a família, primeira linha de defesa da educação moral; a formação do caráter como papel principal da escola, segunda linha de defesa; a relevância do fortalecimento das comunidades e do espírito comunitário; a defesa da saúde pública; a perspectiva cosmopolita do comunitarismo responsivo. (SCHMIDT, 2014, p. 8).

A boa sociedade deve ser formada por relações entre pessoas ("euvocê") e baseada no princípio de que as pessoas são fins e não meios (ETZIONI, 2001, p. 16). A ideia comunitarista contempla que os indivíduos têm direitos individuais e responsabilidade para com os demais membros da sociedade. A boa sociedade está alicerçada em três fundamentos: Estado, mercado e comunidade. A Terceira Via deve buscar o fortalecimento desses elementos ${ }^{12}$ (ETZIONI, 2001, p. 17), sendo "el camino que nos guia hacia la buena sociedad" (ETZIONI, 2001, p. 19), ou seja, a ideia básica é a de que a comunidade visa o fortalecimento da boa sociedade.

A comunidade referida na obra La tercera via, tem correlação ao ideal de sociedade que se descreveu num primeiro momento neste ensaio como ambientada num Direito Social Social Condensado, idealizado por Gurvitch, na medida em que denota que os valores de uma boa sociedade são construtores de laços de afeto, de reconhecimento e de envolvimento na gestão pública.

Por fim, "la idea de que una buena sociedad requiere formulaciones sociales del bien, de que requiere una "virtud republicana", no parece nada extraordinario hasta que se advierte con qué tenacidad se oponen los individualistas a esos conceptos"

\footnotetext{
${ }^{12} \mathrm{O}$ público abrange a forma estatal e a não estatal. $\mathrm{O}$ polo privado diz respeito ao indivíduo, à família, ao particular. A meio caminho, o comunitário, terreno do bem comum, do coletivo, do público não estatal. Nesse enfoque, o setor público (estatal) é o conjunto de órgãos e empresas pertencentes ou controladas pelo Estado, que proporcionam bens e serviços públicos; o setor privado é o conjunto das empresas e organizações particulares, que se caracterizam pela apropriação individual do lucro; o terceiro setor é o conjunto das organizações e instituições criadas e mantidas pela sociedade, que proporcionam bens e serviços de interesse coletivo e cujos resultados são apropriados coletivamente (SCHMIDT, 2014, p. 24).
} 
(ETZIONI, 1999, p. 113). Assim, ampliar a participação dos cidadãos na política tem a ver com a forma como eles decodificam e internalizam normas e valores em relação à política, ou seja, o tipo de cultura política. Em uma avaliação retrospectiva sobre a importância da cultura política na explicação dos fenômenos políticos e sociais, constata-se que ela era vista como algo secundário, negligenciando uma discussão mais aprofundada sobre seu papel na configuração de um sistema democrático e participativo (BAQUERO, 2003, p. 90).

Reforçando a importância da tese de Etzioni e a estima que seus estudos possuem por envolverem a questão comunitária, Schmidt, Helfer e Bora colocam:

[...] o pensamento de Etzioni ilumina, em parte, a própria rememoração empreendida. Sua importância está no fato de proporcionar uma base para pensar o tema da comunidade numa perspectiva democrática, de ordem social marcada pelo equilíbrio entre o indivíduo e a coletividade, de participação ativa dos indivíduos na definição dos assuntos públicos e de ordenamento sociopolítico marcado pelo equilíbrio entre Estado, comunidade e mercado (SCHMIDT; HELFER; BORA, 2013, p. 16-17).

Veja-se que Etzioni diverge de Habermas, pois não concorda com o deliberacionismo, porque entende que os códigos morais não são fruto de consenso, de debate, de deliberação. Assim, mesmo que não se tenha deliberação, o componente moral vai estar, invariavelmente, presente, num genuína "reelaboración de esa cultura moral voluntária sobre qué es lo que la comunidad tolera o censura"(ETZIONI, 2001, p. 64). Poderse-ia dizer: remoralizar a sociedade.

\section{A POSSIBILIDADE DE INTERCONEXÃO ENTRE AS TEORIAS DE GURVITCH E ETZIONI: A INTERAÇÃO SOCIAL COMO DEBATE COMUM}

Neste último ponto é primaz que se realcem, inicialmente, as pretensas diferenças entre as teorias (de direito social condensado e a comunitarista) no que tange ao modo como elas veem e estudam a interação da sociedade cada qual ao seu tempo.

Antes de tudo, cabem listar aqui ao menos sob dois âmbitos, algumas diferenciações (sociais e cronológicas) entre os autores destacados neste 
breve estudo. ${ }^{13}$ Primeiro, o fato de que, em ambos há (cada qual em sua teoria), sob uma ótica social, uma luta contra o individualismo. Em Etzioni, o autor explica, em sua obra, que, de maneira geral, os individualistas são as linhas de pensamentos liberais, os quais sustentam "que cada persona debería formular su propia virtud y que las políticas y las costumbres publicas sólo deberían reflejar los acuerdos que los individuos realizan voluntariamente" (ETZIONI, 1999, p. 31). Em Gurvitch, autor que edificou toda uma teoria no direito de integração, notadamente, o individualismo é rechaçado, pois "excluye lógicamente a la justicia de la ética, es universalismo unilateral, por el contrario, confunde completamente la justicia en el ideal moral (GURVITCH, 2005, p. 107). A teoria liberal maximiza a figura do homem-singular, único capaz de julgar seus interesses (MORAIS, 1997, p. 32) e tal premissa distancia-se totalmente da ideia fulcral de ambas teorias.

Outra perspectiva de relevo é a apartada cronologia de vida dos dois autores. Um, Gurvitch, russo de nascimento, naturalizado francês em 1928. Licenciado e doutor em direito por Sampetesburgo/Petrogrado. Participou, com Lenine, na revolução bolchevique de 1917. Refugiou-se nos Estados Unidos durante a II Guerra Mundial. A partir de 1949 ensinou sociologia na Sorbonne, retomando a tradição de Émile Durkheim. Faleceu em 1965. Ou seja, sua realidade e sua construção teórica deram-se na primeira metade do século XX.

Amitai Etzioni é um sociólogo radicado nos Estados Unidos, possui hoje 85 anos e a construção de sua teoria tem como cenário a segunda metade do século XX, mais especificamente os anos oitenta. Assim, vejase que Etzioni, na realidade, vivenciou mais de perto a cena altamente individualista (americana), pois que ambientado no berço do liberalismo. No caso de Etizioni, sua teoria nasceu mais fortemente a partir da década de noventa do século XX, e tem como influencia os pensadores clássicos da sociologia, como Bubber, Weber, Durkheim, Parsons, bem comoTaylor, Sandel, Walzer e MacIntyre e, destes últimos, constrói a relevância da comunidade e do bem comum, a visão de que o liberalismo não contempla.

$\mathrm{O}$ desafio de falar em interação tem muito a ver com esses paradigmas, afinal, é natural que o impulso de Etzioni em formular uma teoria comunitarista

${ }^{13}$ É claro que não cabem investigações de pesquisas mais profundas dadas as parcas laudas deste artigo, mas servem apenas para localizar o leitor no tempo em que elas foram construídas (e, no caso de Etzioni, em franca construção). 
deu-se numa época em que não era mais justificável a postura altamente arraigada numa concepção puramente particular. Para ele:

El desafío al paradigma comunitario estriba en señalar las vías por las que se pueden mantener los lazos de una comunidad más extensa si eliminar las comunidades miembro. En muchos sentidos, la formación sociológica requerida es similar a la necesaria en las relaciones entre un individuo y una comunidad individual: autonomía antes limitada que sin trabas. (ETZIONI, 1999, p. 227).

A formação sociológica acima descrita é a questão relacional aqui discutida: que se daria "como redes sociales en las que los individuos están unidos entre si por relaciones que cruzan dicha comunidad en todas direcciones, no por relaciones entre uno y otro individuo". (ETZIONI, 1999, p. 153). As comunidades exigem laços de afetos, valores morais em comum (ETZIONI, 2000, p. 24). A transmissão de valores morais é finalidade principal da comunidade. Os grupos baseados somente no interesse são categorizados como grupos de interesse e não comunidade, pois não consideram as pessoas fins em si mesma.

É necessário ver a democracia como gestora de um conjunto de oportunidades e o uso destas requer um estudo diferente que aborde a prática democrática e dos direitos políticos. A democracia não é panaceia (SEN, 2000). As realizações da democracia dependem não só de regras e procedimentos, mas também do modo como as oportunidades são usadas pelos cidadãos, o que, por sua vez, dependerá de vários fatores como o vigor da política multipartidária e o dinamismo dos argumentos morais e da formação de valores. (SEN, 2000, p. 183)

Em Gurvitch a integração social está presente a todo tempo, pois urge que a sociedade que se emancipa, vê seu espaço reconhecido e ali se une para criar normas que vivem ao lado das normativas formais tem, sim, um espaço livre e democr ático no seu entorno. Assim,

En el proceso de integración social se encuentran y se unen dos movimientos diferentes: el todo si integra a si mismo mediante la integración de los miembros en su seno. [...] "Integrar "a un miembro en el "todo" significa: hacerlo participar en este todo como un elemento de generación de su totalidad y según los principios de su unidad, sin someter sin embargo el elemento integrado en un poder unilateral. (GURVITCH, 2005, p. 22). 
Direito é o direito da "transpessoalidade" e da democracia e se contrapõe ao direito individual, atrelado às ideias de coordenação. $\mathrm{O}$ direito como ordem de integração aparece como categoria central na teoria do direito social de Gurvitch, afastando qualquer possibilidade de subordinação, de dependência de organização, pois está fundado sobre a confiança compartilhada pelos membros do grupo, pelo esforço comum e pela ajuda mútua (MORAIS, 1997, p. 53).

Sem necessidade de coerção, subordinação e mesmo de organização, os fatos normativos são construídos pela sociedade sob o prisma de justiça e ao ideal moral. Aqui se localiza a diferenciação das teorias: quando da construção da teoria do direito social, Gurvitch foi vanguarda em idealizar uma tentativa de gestão social de noções de justiça num âmbito local, vez que sua visão de mundo (primeira metade do século XX) era de necessidade de a comunidade unir-se para criar valores de justiça.

Num ótima bem diferente, Etzioni, mais tarde, já tendo vivido o excessivo individualismo norte americano, teorizou que houvesse uma terceira via, divorciada do mercado e do Estado, onde a sociedade (a boa sociedade), por meio de diálogos morais (reflexões morais compartidas) pudesse ser uma alternativa comunitária, sem procedimentos, cujo fundamento ético seria o seu bem estar. Chega-se ao comunitarismo responsivo (comunitário que dão respostas ${ }^{14}$ ), teoria bastante sedutora, pois baseada na ponderação e equilíbrio de fatores. Trata-se de um comunitarismo engajado politicamente - movimento intelectual. Projeta uma renovação da sociedade, onde a comunidade não é mais importante que o individuo, pois se deve buscar um equilíbrio entre direitos individuais e o bem comum. A principal finalidade do comunitarismo de Etzioni é a construção da boa sociedade, na qual as pessoas se tratam como fins e não como instrumento para atingir outros fins ${ }^{15}$. Portanto, o imperativo da boa sociedade é a harmonia entre Estado, comunidade e mercado. (SCHMIDT; HELFER; BORBA, 2013, p. 38).

Veja-se que, em Gurvitch, os procedimentos poderiam ser uma extensão de sua teoria, pois propõe um direito como fato social, que encontra

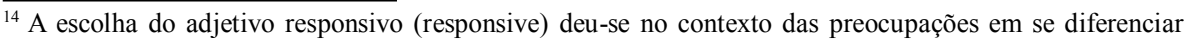
de outras formas de comunitarismo, particularmente do modelo comunista e do modelo asiático. Enquanto aquele se caracterizou pelo viés estatizante e coletivista, este, segundo Bell (2009 apud SCHMIDT, 2014, p. 8-9), distingue-se pela ênfase na família, na harmonia social e na precedência do social, sendo que ambas as perspectivas rejeitam os valores liberais da autonomia individual, da sociedade civil e das liberdades políticas.

${ }^{15} \mathrm{O}$ autor fala das relações Eu-nós, sem deixar de considerar as relações eu-coisas.
} 
sua legitimidade a partir da própria sociedade, estabelecendo-se nitidamente uma lógica reflexiva, segundo a categoria habermasiana, pois os autores sociais são simultaneamente autores e destinatários do direito. Por assim, dizer, "o direito encontra sua garantia no reconhecimento social, a partir da atuação reflexiva dos quadros sociais estruturados ou não”. (HERMANY, 2007, p.31).

Por sua vez, para o comunitarismo, o viés não é a proposta legiferante, mas um caminho alternativo às duas posições já consolidadas (e extremas) do individualismo do mercado e da ordem social do Estado. Essa busca não dá por meio de deliberações e consensos (atuação reflexiva), mas de uma plataforma construída de consolidações prospectivas assim estabelecidas, como vimos no ponto anterior:

As comunidades exercem uma função moral fundamental. Além da voz moral interior (pessoal), há a voz moral comunitária, exterior ao eu e que pode reforçar a voz pessoal. Ao compartilhar e reafirmar os valores comunitários, estimulando os seus membros a orientarem sua conduta por eles e censurando-os quando não o fazem, as comunidades são elementos indispensáveis para a precedência dos meios normativos sobre os meios coercitivos. Quanto mais eficazes são os meios normativos, menor é a necessidade de coerção. Investigações empíricas mostram que há forte conexão entre vínculo afetivo e voz moral (SCHMIDT, 2014, p. 8).

Vê-se que a proposta comunitarista não traz os procedimentos como possibilidades, mas, a relevância do fortalecimento dos vínculos das comunidades como base de sua plataforma. Em que pese este estudo não ser completo (e nem buscar sê-lo), denota-se que, apesar dos diferentes momentos das construções das teorias aqui levantadas, elas convergem na questão da interação social, na necessidade de romper com ideias particularistas.

A relevância em abordar as teorias é notar que, em ambas, há uma busca pela aproximação da sociedade, mesmo em papeis apartados. Antes mesmo de o pretenso nascimento de um Estado Social ${ }^{16}$, Gurvitch um direito social que tinha como pressuposto uma auto-regulação comunitária,

\footnotetext{
${ }^{16}$ Em que pese ser vasto o estudo acerca do Estado Providência (Walfare State), é imperioso destacar aqui que fora "a instituição política inventada pelo capitalismo para (tentar) compatibilizar as promessas da modernidade com o desenvolvimento do sistema capitalista" (STRECK, 2007,p. 22).
} 
convivendo com a normatização estatal, a fim de buscar romper com o paradigma liberal-individualista. $\mathrm{O}$ desenho de sociedade pretendida por Gurvitch, contida numa ambiência de Estado Democrático e uma proposta ativa num processo de elaboração de fatos normativos cujo fulcro é reger a vida em comunidade.

Por sua vez, a boa sociedade, trabalhada por Etzioni, embora não referendadora de construção normativa no ambiente social, traz consigo um projeto ideológico apresentando-se como terceira via, em favor da renovação do projeto do welfare state e, "no terreno da política interna norte-americana, o movimento colocou-se como alternativa aos excessos dos neoconservadores por um lado e dos libertários por outro. Economicamente, faz a defesa do mercado regulado por valores sociais, opondo-se claramente ao neoliberalismo" (SCHMIDT, 2014, p. 9). Esta, talvez, seja a maior aproximação da busca de ambos os autores: a reconstrução de um projeto de Estado Social que, de fato, nunca houve e jamais correspondeu as promessas sociais alicerçadas na sua "ideia" propositiva.

Em ambas a democracia está presente. Para Etzioni, as sociedades democráticas costumam ser menos opressoras porque as pessoas podem escolher os grupos a que desejam pertencer, porém isso não é uma verdade inafastável. (ETZIONI, 2000, p. 25). Para Gurvitch, enfim, somente na constância de uma democracia haveria um direito como integração, um direito interior.

Por fim, como fecho a este ensaio, há que se reforçar que a aproximação maior de ambas as teses é a ideia de democracia. O sistema democrático é o único que pressupõe o convívio das diferenças. E por trás da diversidade de concepções avultam valores políticos - igualdade e liberdade - sem os quais perde a razão de ser. A liberdade é fundamento e limite da democracia, eis que a liberdade não pode ser posta em causa e a maioria é somente conjuntural. (MIRANDA, 1996, p. 194).

A busca pela emancipação social e a integração da sociedade é a busca para a transformação dos estados das coisas, em cada momento historio onde as teorias foram erigidas. A ideia de democracia representativa esteve presente desde a Idade Média, embora sua conceituação tenha surgido com o Estado Contemporâneo Constitucional. Com o passar dos tempos, passou-se a diagnosticar insuficiências em seu modelo, e, desde antes da promulgação da Constituição de 1988 já se visualizava a adoção da democracia participativa. Mas quando o modelo representativo de 
democracia se esgota? Algumas causas de esgotamento são consenso entre os cientistas políticos, como, por exemplo, a fragilidade da formação dos representantes, a concentração de poderes no Poder Executivo, a corrupção, a ausência de uma formação política por parte dos eleitores, e muitas outras.

A contribuição do comunitarismo é relevante para a revitalização democrática. O fortalecimento das comunidades é requisito para o fortalecimento da comunidade política, serve-lhe de apoio e espaço de desenvolvimento de habilidades cívicas. As comunidades se formam e se fortalecem no espaço público, constituindo-se em contraponto às tendências individualistas das sociedades atuais. Ao destacar a importância do bem comum, o comunitarismo responsivo não relega a a autonomia individual, e sim enfatiza a necessidade do equilíbrio entre indivíduo e comunidade.

Por sua vez, ao se debruçar sobre a teoria gurvitchiana depara-se com um avanço em relação ao simples papel regulador e promotor do bem estar social, dando azo a uma autorregulamentação comunitária que convive com a normatização estatal, e, portanto, ambientada sofisticadamente na ideia democracia.

\section{CONSIDERAÇÕES FINAIS}

O presente artigo buscou articular, primeiramente a teoria de Georges Gurvitch acerca do Direito Social condensado, explicitando alguns referenciais importantes que permeiam o papel da sociedade naquele enfoque. $\mathrm{Na}$ sequencia foi trabalhado algumas notas sobre a teoria de Amitai Etzioni, chamada de comunitarismo responsivo e seus referenciais. Por fim, o ensaio tratou de aproximar as questões comuns em que as teorias- cada qual construída em seu tempo- debatem, para , traçar algumas interconexões.

Em que pese o desenrolar em apertadas laudas, concluiu-se que, apesar das notáveis diferenças entre seus autores (incluindo a cronologia de vida), as teorias buscam algo em comum: a integração social numa ambiente democrático. $\mathrm{O}$ rechaço às posturas extremistas, que imprimem o individualismo é a forca motriz para a construção de um direito autorregulado pela sociedade- por Gurvitch- e, também, por Etzioni, pra o desenho de uma Plataforma que perfila uma terceira via ao individualismo e ao social conservadorismo.

Pode-se dizer que a concepção de Gurvitch acerca do direito social permite que se estabeleçam elementos de integração entre o processo de 
coordenação e integração dos atores sociais no processo de organização da sociedade, ambientados num Estado Democrático enquanto o estudo do comunitarismo traz consigo algumas premissas que só fortalecem a ambiência democrática, tais como a precedência da comunidade sobre o indivíduo, a oposição ao individualismo (e ao gigantismo estatal) e a primazia dos valores pessoais sobre os valores de mercado.

A construção do ideário comunitarista implica uma mudança na educação atual dos cidadãos, nas formas de comportamento e no desenvolvimento de valores, estimulando pluralidade, a convivência pacífica, as práticas responsáveis de relacionamento e de solidariedade. Nesse mesmo sentido, para a construção de um Direito Social Condensado - os cidadãos para gestarem conjuntamente seus espaços por meio de uma legislação social - a ideia de cidadãos autônomos e reflexivos (autoeducação) permanece.

\section{REFERÊNCIAS}

BAQUERO, Marcello. Construindo uma outra sociedade: o capital social na estruturação de uma cultura política participativa no Brasil. Revista de Sociologia e Política, Curitiba, n. 21, p. 83-108, nov. 2003. Disponível em: $<$ http://www.scielo.br/pdf/rsocp/n21/a07n21.pdf $>$. Acesso em: 8 abr. 2014.

ETZIONI, Amitai. La nueva regla de oro: comunidad y moralidad em uma sociedad democrática. Barcelona: Paidós, 1999.

ETZIONI, Amitai. La tercera via hacia uma buena sociedad: propuestas desde el comunitarismo. Sagasta: Trotta, 2000.

ETZIONI, Amitai. La tercera vía hacia uma buena sociedad: propuestas desde el comunitarismo. Madrid: MinimaTrotta, 2001.

GARCÍA-PELAYO, Manuel. Las transformaciones del estado contemporáneo. Madrid: Alianza Editorial, 1996.

GURVITCH, Georges. La idea de derecho social. Noción del sistema de derecho social, historia doctrinal desde el siglo XVII 
hasta el fin del siglo XIX. Tradução de José Luis Monereo Pérez e Antônio Márquez Prieto. Comares: Granada, 2005.

HABERMAS, Jürgen. Direito e democracia: entre facticidade e validade II. 2. ed. Tradução de Flávio Beno Siebeneichler. Rio de Janeiro: Tempo Brasileiro, 2003.

HERMANY, Ricardo. (Re)discutindo o espaço local: uma abordagem a partir do direito social de Gurvitch. Santa Cruz do Sul: Edunisc: 2007.

MARQUES, Jaqueline. A reconfiguração do estado-providência. Gestão e Desenvolvimento, Viseu, n. 15-16, p. 105-119, 2008.

MIRANDA, Jorge. Ciência política: formas de governo. Lisboa: Pedro Ferreira Editor, 1996.

MORAIS, José Luis Bolzan. A Idéia de direito social: o pluralismo jurídico de Georges Gurvitch. Porto Alegre: Livraria do Advogado, 1997.

SAN RÓMAN, José Antonio Ruiz; PEDROSA, Leticia Porto. Conflicto ético,diálogo e intervención social: la propuesta de "diálogos morales"de Amitai Etzioni. Comunitania: Revista Internacional de Trabajo Social y Ciencias Sociales, Madrid, v. 3, p. 44-53, Enero 2012.

SANTOS, Boaventura de Souza. Contexto e princípios de uma discussão sobre as políticas sociais em Portugal. In: Seminário Europeu Políticas E Instrumentos De Combate À Pobreza Na União Europeia: A Garantia De Um Rendimento Mínimo, 2000, Almansil. Actas... Almansil: Presidência Portuguesa da União Europeia, 2000.

SCHMIDT, João Pedro; HELFER, Inácio; BORBA, Ana Paula de Almeida de. Comunidade e comunitarismo: temas em debate. Curitiba: Multideia, 2013.

SCHMIDT, João Pedro. Amitai Etzioni e o paradigma comunitarista: da sociologia das organizações ao comunitarismo responsivo. Lua Nova, São Paulo, n. 91, mar. 2014. 
SEN, Amartya. Desenvolvimento como liberdade. São Paulo: Cia das Letras, 2000.

STRECK, Lenio Luiz. Hermenêutica Jurídica em 'Crise Uma explosão hermenêutica da construção do Direito'. 7.ed. rev. e atual. Porto Alegre: Livraria do Advogado, 2007.

Submetido em 06/04/2015

Aprovado em 18/07/2015

Como citar: FONTANA, Eliane; HERMANY, Ricardo. O direito social condensado em Gurvitch e o comunitarismo de Ezioni: notas acerca de uma interconexão possível. Scientia Iuris, Londrina, v.19, n.2, p. 51-72, dez.2015. DOI: 10.5433/2178-8189.2015v19n2p51. ISSN 2178-8189. 